\title{
SISTEM PENDUKUNG KEPUTUSAN BANTUAN KELOMPOK USAHA BERSAMA (KUBE) PADA DINAS KESEJAHTERAAN SOSIAL PROVINSI BENGKULU
}

\author{
Devi Sartika \\ Program Studi Informatika Fakultas Ilmu Komputer Universitas Dehasen Bengkulu \\ Jalan Meranti Raya No.32 Kelurahan Sawah Lebar Kota Bengkulu Telp. 22027 Fax. (0736) 341139 \\ devisartika86@gmail.com
}

\begin{abstract}
Abstrak: Tujuan penelitian ini dilakukan yaitu untuk membuat Sistem Pendukung Keputusan Bantuan Kelompok Usaha Bersama (KUBE) Pada Dinas Kesejahteraan Sosial Provinsi Bengkulu. Tempat penelitian dilaksanakan di Dinas Kesejahteraan Sosial Provinsi Bengkulu. Kelompok Usaha Bersama (KUBE) merupakan media dan sekaligus metode dalam penanggulangan kemiskinan perkotaan. KUBE ini diarahkan untuk terciptanya aktifitas sosial dan ekonomi guna meningkatkan kesejahteraan sosial mereka.Dalam proses pemberian bantuan Kelompok Usaha Bersama (KUBE) pada Dinas Kesejahteraan Sosial Provinsi Bengkulu tidak melakukan seleksi yang terlalu ketat dalam hal menindak lanjuti siapa yang berhak mendapatkan bantuan atau yang tidak berhak mendapatkan bantuan. Terkadang bantuan diberikan karena masih ada hubungan keluarga. Hal ini justru menimbulkan suatu masalah bagi masyarakat yang harusnya menerima bantuan, tapi malah tidak menerima bantuan, sehingga kesenjangan sosial pun terjadi. Untuk mengatasi hal tersebut, penulis membuat suatu sistem pendukung keputusan yang dapat menentukan siapa saja yang layak mendapatkan bantuan dan tidak layak mendapatkan bantuan berdasarkan kriteria-kriteria penilaian yang telah ditetapkan oleh Dinas Kesejahteraan Sosial Provinsi Bengkulu. Sistem pendukung keputusan bantuan kelompok usaha bersama (KUBE) Pada Dinas Kesejahteraan Sosial Provinsi Bengkulu merupakan aplikasi yang dapat membantu dalam mengambil keputusan kelayakan pemberian bantuan kepada masing-masing Kelompok Usaha Bersama (KUBE). Aplikasi ini telah menyediakan 18 (delapan belas) kriteria penilaian yang dinilai pada masing-masing KUBE. Hasil dari penilaian tersebut diproses menggunakan metode Weighted Product (WP), kemudian melakukan perankingan berdasarkan nilai WP yang paling tinggi.

Kata Kunci: Sistem, Pendukung, Keputusan, KUBE, Dinas, Kesejahteraan, Sosial, Bengkulu.
\end{abstract}

Abstrack: The purpose of this research is done is to make the Decision Support System Assistance Business Group (KUBE) In Bengkulu Provincial Social Welfare Office. Place of research conducted at the Department of Social Welfare Bengkulu Province. Business Group (KUBE) is a media and at the same methods in urban poverty reduction. $K U B E$ is directed to the creation of social and economic activities in order to improve the social welfare relief process mereka.Dalam Business Group (KUBE) at the Department of Social Welfare did not make the selection of Bengkulu province were too strict in terms of following up on who is eligible for assistance or who are not entitled to help. Sometimes the help is given because there was a family relationship. It is precisely to pose a problem for people who should receive assistance, but did not even receive assistance, so that the social gap ensued. To overcome this, the author makes a decision support system that can determine who will be eligible for assistance and do not deserve aid assessment based on the criteria established by the Social Welfare Department of Bengkulu province.

Decision support systems help business groups (KUBE) At the Social Welfare Department Bengkulu Province is an application that can assist in making decisions feasibility of providing assistance to each Business Group (KUBE). This application has to provide 18 (eighteen) assessment criteria are assessed at each $K U B E$. The results of these assessments are processed using the method of Weighted Product (WP), then perform a ranking based on the value of the highest WP

Keywords: Decision, Support, Systems, KUBE, Social, Welfare, Department of, Bengkulu. 
Jurnal Pseudocode, Volume VII Nomor 1, Februari 2020, ISSN 2355-5920, e-ISSN 2655-1845 www.ejournal.unib.ac.id/index.php/pseudocode

\section{PENDAHULUAN}

Sistem Pendukung Keputusan merupakan Computer Based Information System (CBIS) yang interaktif, fleksibel, mudah disesuaikan (dapat beradaptasi) yang secara khusus dikembangkan untuk mendukung penyelesaian dari permasalah yang tidak terstruktur untuk meningkatkan pembuatan keputusan (Dyah, 2009:333).

\section{Kelompok Usaha Bersama (KUBE)} merupakan media dan sekaligus metode dalam penanggulangan kemiskinan perkotaan. KUBE ini diarahkan untuk terciptanya aktifitas sosial dan ekonomi guna meningkatkan kesejahteraan sosial mereka Dalam proses pemberian bantuan Kelompok Usaha Bersama (KUBE) pada Dinas Kesejahteraan Sosial Provinsi Bengkulu tidak melakukan seleksi yang terlalu ketat dalam hal menindaklanjuti siapa yang berhak mendapatkan bantuan atau yang tidak berhak mendapatkan bantuan Terkadang bantuan diberikan karena masih ada hubungan keluarga. Hal ini justru menimbulkan suatu masalah bagi masyarakat yang harusnya menerima bantuan, tapi malah tidak menerima bantuan, sehingga kesenjangan sosial pun terjadi. Untuk mengatasi hal tersebut, penulis membuat suatu sistem pendukung keputusan yang dapat menentukan siapa saja yang layak mendapatkan bantuan dan tidak layak mendapatkan bantuan berdasarkan kriteria-kriteria penilaian yang telah ditetapkan oleh Dinas Kesejahteraan Sosial Provinsi Bengkulu.

\section{LANDASAN TEORI}

\section{A. Pengertian Sistem Pendukung Keputusan}

Menurut Oktaputra (2014 : 2), sistem Pendukung Keputusan atau sering disebut Decision Support System (DSS) adalah Sistem berbasis model yang terdiri dari prosedurprosedur dalam pemrosesan data dan pertimbangannya untuk membantu manajer dalam mengambil keputusan. Agar berhasil mencapai tujuannya maka sistem tersebut harus sederhana, mudah untuk dikontrol, mudah beradaptasi lengkap pada hal-hal penting dan mudah berkomunikasi dengannya.

Secara implisit juga berarti bahwa sistem ini harus berbasis komputer dan digunakan sebagai tambahan dari kemampuan penyelesaian masalah dari seseorang. Menurut Christian (2014 : 4), Decision Support System didefinisikan sebagai sistem komputer yang mampu memberikan kemampuan baik kemampuan pemecahan masalah maupun kemampuan pengkomunikasian untuk masalah semi terstruktur.

\section{B. Pengertian Metode Weighted Product}

Menurut Alfita (2012 : 2), Metode weighted product memerlukan proses normalisasi karena metode ini mengalikan hasil penilaian setiap atribut. Hasil perkalian tersebut belum bermakna jika belum dibandingkan (dibagi) dengan nilai standart. Bobot untuk atribut manfaat berfungsi sebagai pangkat positif dalam proses perkalian, sementara bobot biaya berfungsi sebagai pangkat negative. Metode weighted product menggunakan perkalian untuk menghubungkan rating atribut, dimana ranting setiap atribut.

\section{Pengertian Kelompok Usaha Bersama (KUBE) \\ Dalam Buku Pedomanan Pelaksanaan} Penanggulangan Kemiskinan Perkotaan Melalui Usaha Ekonomi Produktif Kelompok Usaha Bersama (2014: 7), Kelompok Usaha Bersama (KUBE) merupakan media dan sekaligus metode dalam penanggulangan kemiskinan perkotaan. KUBE ini diarahkan untuk terciptanya aktifitas 
Jurnal Pseudocode, Volume VII Nomor 1, Februari 2020, ISSN 2355-5920, e-ISSN 2655-1845

www.ejournal.unib.ac.id/index.php/pseudocode

sosial dan ekonomi guna meningkatkan kesejahteraan sosial mereka. Dari sisi sosial, melalui KUBE fakir miskin diarahkan untuk dapat berinteraksi sosial dan saling peduli satu sama lain dalam memecahkan permasalahan dan memenuhi kebutuhan. Kemudian dari sisi ekonomi melalui KUBE fakir miskin diarahkan untuk memiliki sumber penghasilan yang tetap, layak dan berkelanjutan, memiliki aset, terpenuhinya kebutuhan dasar dan aksesibilitas terhadap pelayanan sosial Adapun kriteria anggota Kelompok Usaha Bersama (KUBE), antara lain:

\section{Keluarga Miskin :}

a. Luas lantai bangunan tempat tinggal kurang dari $8 \mathrm{~m} 2$ per-orang

b. Jenis lantai bangunan tempat tinggal terbuat dari tanah/ bambu/ kayu murahan.

c. Jenis dinding tempat tinggal terbuat dari bambu/rumbia/kayu berkualitas rendah/ tembok tanpa plester.

d. Sumber penerangan rumah tangga tidak menggunakan listrik.

e. Sumber air minum berasal dari sumur/ mata air tidak terlindungi/ sungai/ air hujan.

f. Bahan bakar untuk memasak sehari-hari adalah kayu bakar/ arang/ minyak tanah

g. Hanya mengkonsumsi daging/ ayam/susu satu kali dalam seminggu

h. Hanya membeli 1 (satu) stel pakaian baru dalam setahun

i. Hanya sanggup makan sebanyak 1 (satu)/ 2 (dua) kali dalam sehari

j. Tidak sanggup membayar biaya pengobatan di Puskesmas/ Poliklinik

2. Kepala keluarga laki-laki atau perempuan yang masih produktif, umur tidak lebih dari
58 tahun, mampu latih dan memiliki semangat kerja

3. Memiliki bukti-bukti sebagai penduduk setempat(KTP, KK, Keterangan Lurah)

4. Bersedia mengikuti proses kegiatan sejak awal sampai akhir program

5. Mempunyai embrio usaha

D. Bahasa Pemrograman Visual Basic .Net

Microsoft Visual Basic (sering disingkat sebagai $V B$ saja) merupakan sebuah bahasa pemrograman yang bersifat event driven dan menawarkan Integrated Development Environment (IDE) visual untuk membuat program aplikasi berbasis sistem operasi Microsoft Windows dengan menggunakan model pemrograman Common Object Model (COM). Visual Basic merupakan turunan bahasa BASIC dan menawarkan pengembangan aplikasi komputer berbasis grafik dengan cepat, akses ke basis data menggunakan Data Access Objects (DAO), Remote Data Objects.

(RDO), atau ActiveX Data Object (ADO), serta menawarkan pembuatan kontrol ActiveX dan objek ActiveX (Adelia, 2011:114). Visual Basic .Net adalah generasi selanjutnya dari Visual Basic. Visual Basic .Net memungkinkan untuk membangun aplikasi database client atau server performa tinggi dan sangat cocok didampingkan dengan perangkat lunak $S Q L$ Server. .NET Framework merupakan model platform yang memudahkan dalam membangun lingkungan aplikasi yang terdistribusi di Internet. Platform .Net Framework terdiri dari dua bagian utama (Junindar, 2008:3).

Halaman menu utama dari Visual Basic .NET, seperti tampak pada gambar.1. di bawah ini. 
Jurnal Pseudocode, Volume VII Nomor 1, Februari 2020, ISSN 2355-5920, e-ISSN 2655-1845 www.ejournal.unib.ac.id/index.php/pseudocode

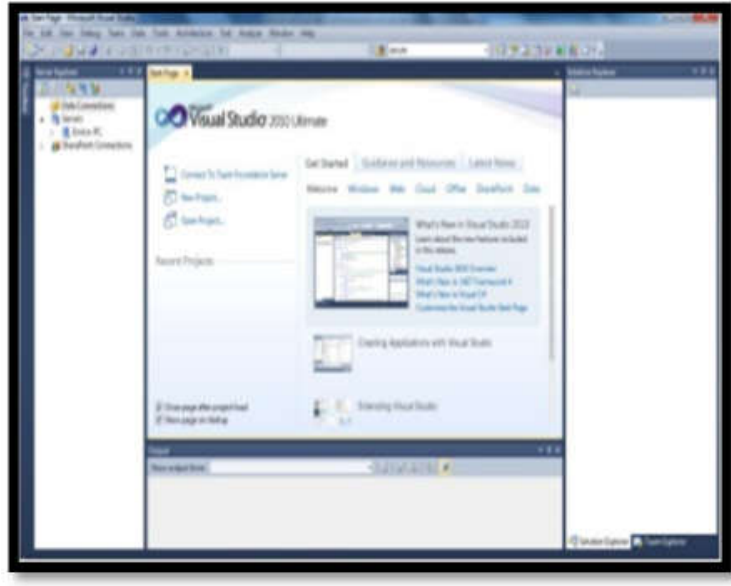

Gambar 1. Tampilan Halaman Menu Utama Visual Basic .Net

Untuk membuat Project baru pilih New Project untuk menampilkan dialog New Project seperti berikut

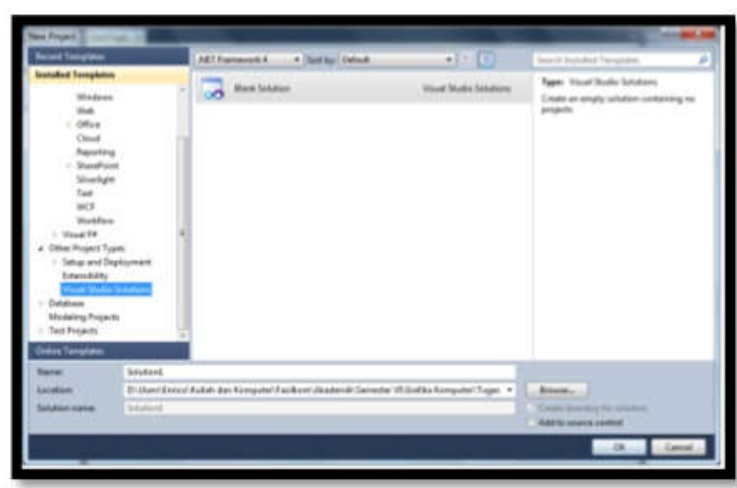

Gambar 2. Menu Project

E. SQL Server 2008r2

SQL (Structured Query Language) adalah sebuah bahasa yang dipergunakan untuk mengakses data dalam basis data relasional. Bahasa ini secara de facto merupakan bahasa standar yang digunakan dalam manajemen basis data relasional. Saat ini hampir semua server basis data yang ada mendukung bahasa ini untuk melakukan manajemen datanya (Adelia, 2011:115).

SQL Server merupakan suatu Relational Database Management Sistems (RDBMS) yang digunakan untuk menyimpan data. Data yang disimpan pada database bisa dalam skala kecil maupun besar. Selain itu, penyajiannya merupakan penyajian pada level fisik karena kita akan menyimpan langsung data pada database dengan kondisi yang sebenarnya, yaitu disimpan pada tabel apa, kolom mana, dan menggunakan tipe data saat penyimpanan (Hernita, 2010:5).

F. Konsep Perancangan Database

Pangkalan data atau basis data (bahasa Inggris: database), atau sering pula dieja basis data, adalah kumpulan informasi yang disimpan di dalam komputer secara sistematik sehingga dapat diperiksa menggunakan suatu program komputer untuk memperoleh informasi dari basis data tersebut. Perangkat lunak yang digunakan untuk mengelola dan memanggil kueri (query) basis data disebut sistem manajemen basis data (Database Management System/DBMS). Sistem basis data dipelajari dalam ilmu informasi (Hernita, 2010:15).

Pendefinisian basis data meliputi spesifikasi berupa tipe data, struktur, dan juga batasanbatasan data yang akan disimpan. Basis data merupakan aspek yang sangat penting dalam sistem informasi di mana basis data merupakan gudang penyimpanan data yang akan diolah lebih lanjut. Basis data menjadi penting karena dapat menghindari duplikasi data, hubungan antar data yang tidak jelas, organisasi data, dan juga update yang rumit (Hernita, 2010:16)

\section{G. Data Flow Diagram (DFD)}

Diagram Arus Data atau yang sering disebut sebagai Data Flow Diagram (DFD) merupakan alat perancangan sistem yang berorientasi pada alur data dengan konsep dekomposisi dapat digunakan untuk penggambaran analisa maupun rancangan sistem yang mudah dikomunikasikan oleh profesional sistem kepada pemakai maupun pembuat program. Diagram Arus Data mempunyai empat komponen utama yaitu entitas 
Jurnal Pseudocode, Volume VII Nomor 1, Februari 2020, ISSN 2355-5920, e-ISSN 2655-1845

www.ejournal.unib.ac.id/index.php/pseudocode

(entities), proses (process), media penyimpanan (data storage) dan arus data (data flows). Ke empat komponen tersebut menggambarkan arus sistem agar mudah dipahami (Haviluddin, 2009:1)

H. Entity Relationship Diagram (ERD)

Entity relationship (ERD) data model didasarkan pada persepsi terhadap dunia nyata yang tersusun atas kumpulan objek-objek dasar yang disebut entitas dan hubungan antar objek. Entitas adalah sesuatu atau objek dalam dunia nyata yang dapat dibedakan dari objek lain. Misal: mahasiswa, dan matakuliah. Entitas digambarkan dalam basis data dengan kumpulan atribut. Misalnya: nim, nama, alamat, dan kota. Relasi adalah hubungan antara beberapa entitas. Misalnya: relasi menghubungkan mahasiswa dengan mata kuliah yang diambilnya (Octafian, 2011:150).

\section{METODOLOGI PENELITIAN}

Adapun metode penelitian yang digunakan penulis adalah metode pengembangan sistem. Metode pengembangan sistem yang digunakan adalah Waterfall. Adapun tahapan-tahapan metode waterfall, antara lain:

\section{Analisis}

Langkah ini merupakan analisa terhadap kebutuhan sistem. Pengumpulan data dalam tahap ini bisa malakukan sebuah penelitian, wawancara atau study literature.

\section{Design}

Proses desain akan menerjemahkan syarat kebutuhan ke sebuah perancangan perangkat lunak yang dapat diperkirakan sebelum dibuat coding.

3. Coding dan Testing

Coding merupakan penerjemahan design dalam bahasa yang bisa dikenali oleh computer.

\section{Penerapan}

Tahapan ini bisa dikatakan final dalam pembuatan sebuah sistem. Setelah melakukan analisa, design dan pengkodean maka sistem yang sudah jadi akan digunakan oleh user.

5. Pemeliharaan

Perangkat lunak yang sudah disampaikan kepada pelanggan pasti akan mengalami perubahan.

\section{HASIL DAN PEMBAHASAN}

A. Hasil

Sistem pendukung keputusan bantuan kelompok usaha bersama (KUBE) Pada Dinas Kesejahteraan Sosial Provinsi Bengkulu merupakan aplikasi yang dapat membantu dalam mengambil keputusan kelayakan pemberian bantuan kepada masing-masing Kelompok Usaha Bersama (KUBE). Aplikasi ini telah menyediakan 18 (delapan belas) kriteria penilaian yang dinilai pada masing-masing KUBE. Hasil dari penilaian tersebut diproses menggunakan metode Weighted Product (WP), kemudian melakukan perankingan berdasarkan nilai WP yang paling tinggi, seperti tampak pada Gambar 3.

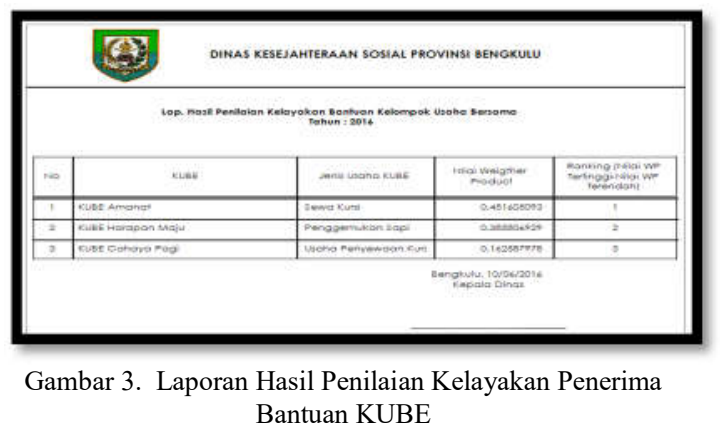


Jurnal Pseudocode, Volume VII Nomor 1, Februari 2020, ISSN 2355-5920, e-ISSN 2655-1845 www.ejournal.unib.ac.id/index.php/pseudocode

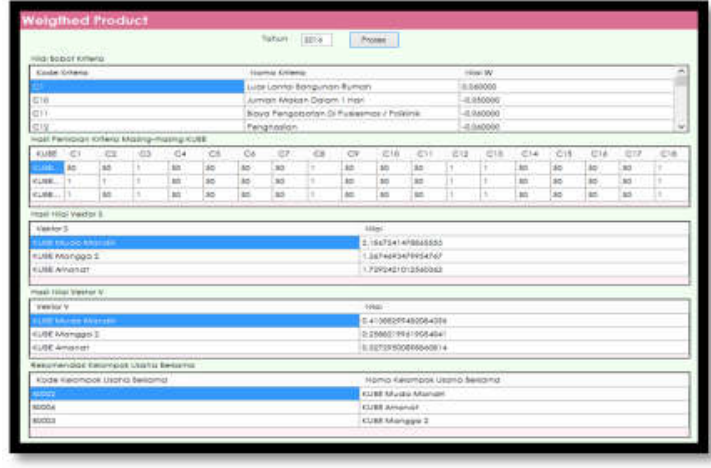

Gambar 4. Proses Perhitungan WP

\section{B. Halaman Menu Login}

Menu login merupakan form yang pertama kali tampil ketika menjalankan aplikasi ini. Menu login digunakan sebagai otentikasi username dan password, agar dapat masuk ke menu utama. Adapun form menu login terlihat pada Gambar 5 di bawah ini :

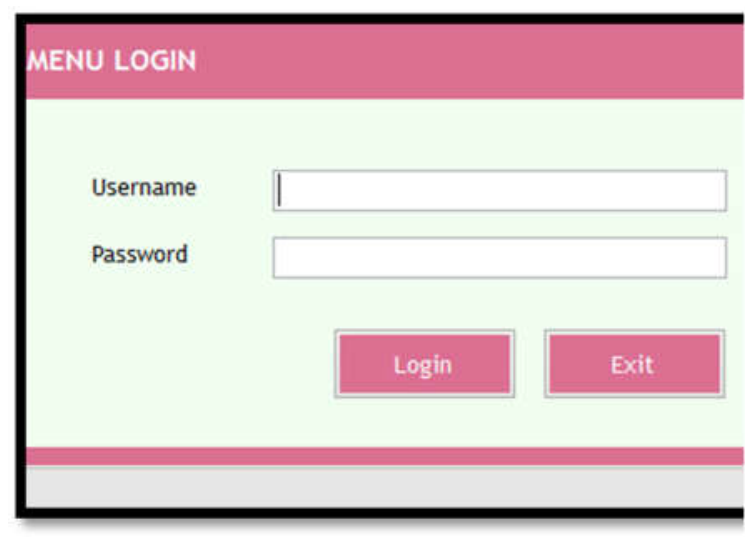

Gambar 5. Halaman Menu Login

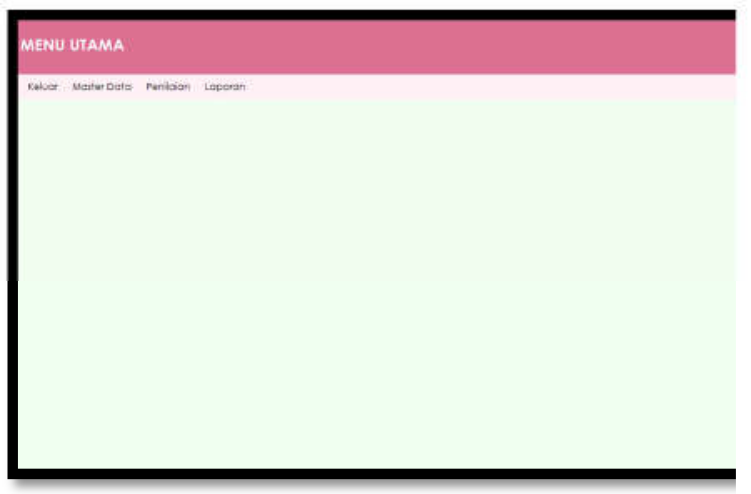

Gambar 6. Halaman Menu Utama

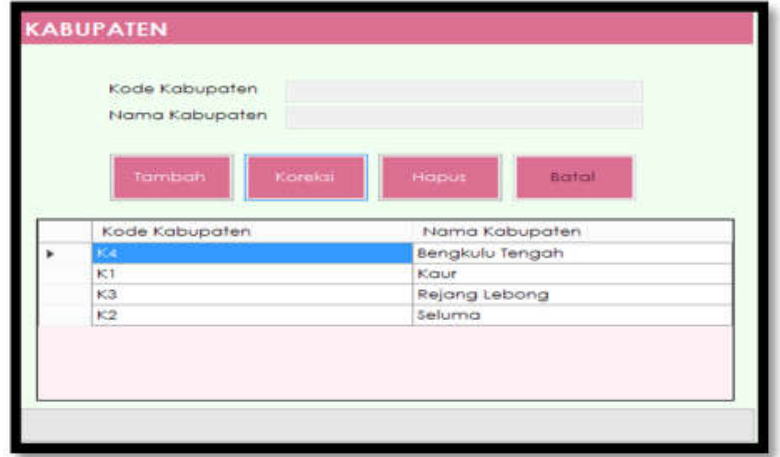

Gambar 7. Halaman Form Data Kabupaten

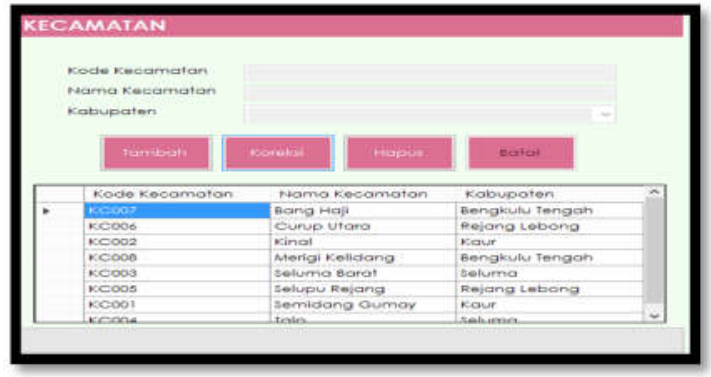

Gambar 8. Form Data Kecamatan

C. Tampilan Menu Pembayaran

Form data kelurahan digunakan untuk mengolah data kelurahan di kecamatan di masing-masing kabupaten di wilayah Provinsi Bengkulu. Pengolahan data dapat dilakukan dengan cara menambah, mengoreksi dan menghapus data kelurahan. Adapun form data kelurahan, terlihat pada Gambar 9 di bawah ini:

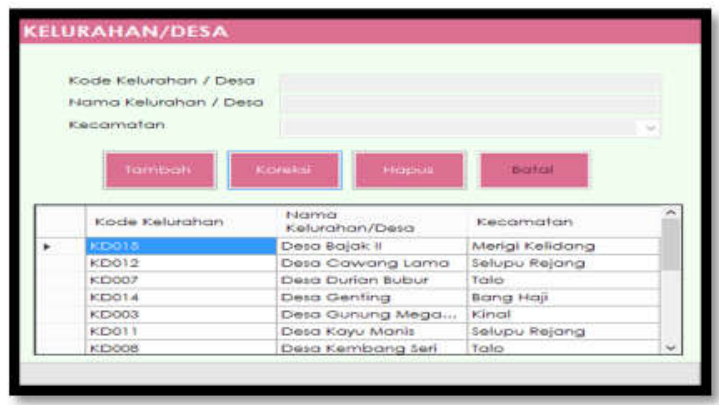

Gambar 9. Form Data Kelurahan

\section{Menu Laporan}

Form data KUBE digunakan untuk mengolah data KUBE di kelurahan di kecamatan di masing-masing kabupaten di wilayah Provinsi Bengkulu. Pengolahan data dapat dilakukan dengan cara menambah, mengoreksi dan 
Jurnal Pseudocode, Volume VII Nomor 1, Februari 2020, ISSN 2355-5920, e-ISSN 2655-1845

www.ejournal.unib.ac.id/index.php/pseudocode

menghapus data KUBE. Adapun form data KUBE Gambar 10.

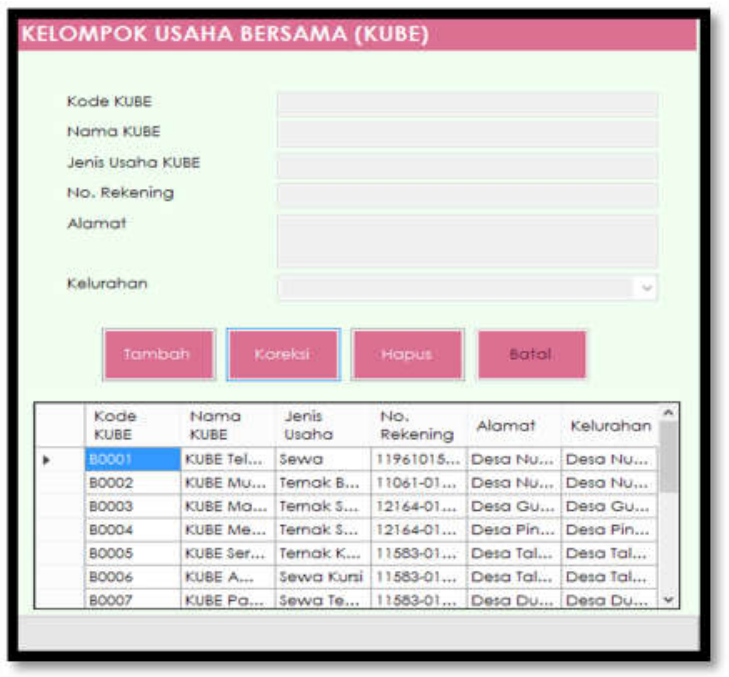

Gambar 10. Form Data KUBE

\section{E. Sub Menu Pengaturan}

Form data anggota KUBE digunakan untuk mengolah data anggota KUBE di kelurahan di kecamatan di masing-masing kabupaten di wilayah Provinsi Bengkulu. Pengolahan data dapat dilakukan dengan cara menambah, mengoreksi dan menghapus data anggota KUBE. Adapun form data anggota seperti terlihat pada Gambar 11.

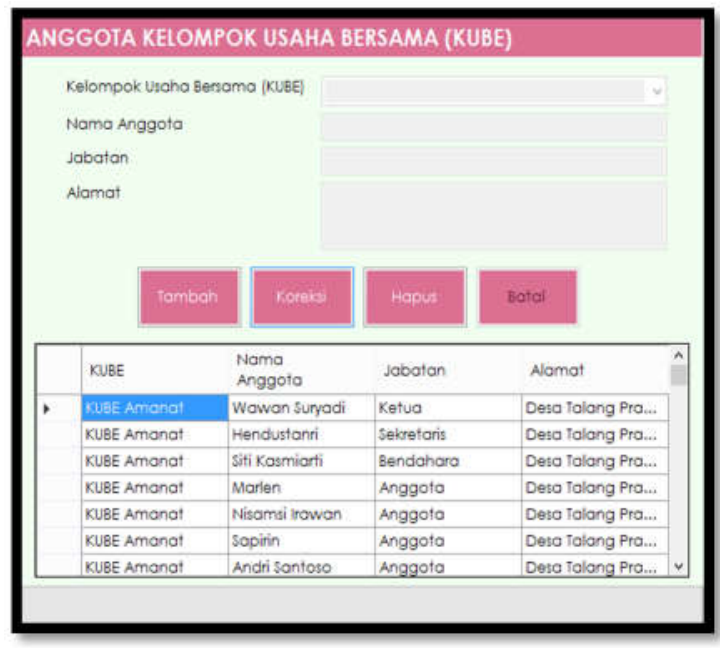

Gambar 11. Form Data Anggota KUBE

F. Kompilasi Sistem

1. Form data kriteria digunakan untuk mengolah data kriteria. Pengolahan data dapat dilakukan dengan cara menambah, mengoreksi dan menghapus data kriteria.

Adapun form data kriteria.

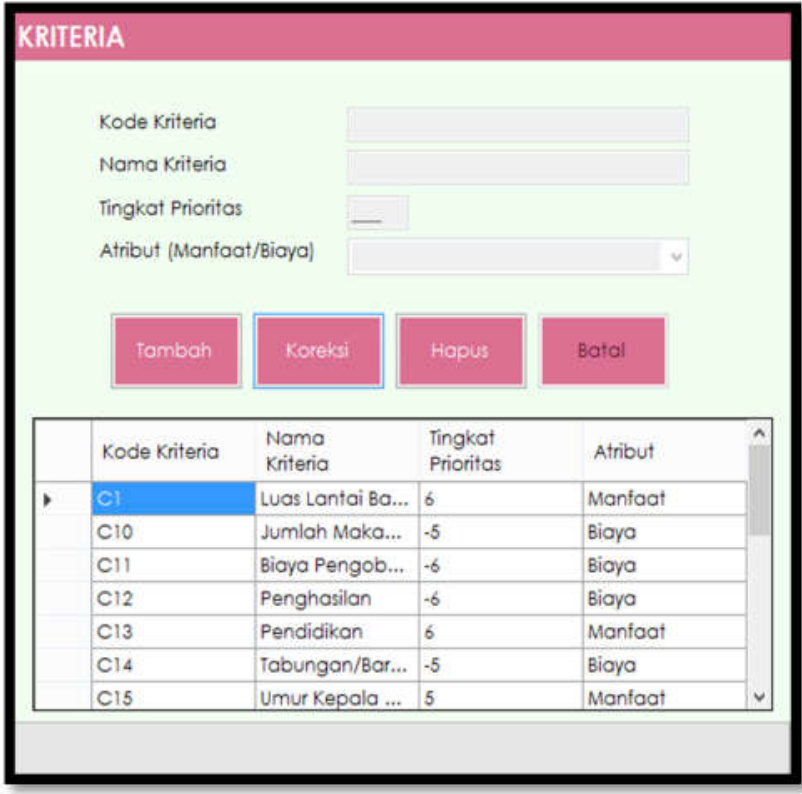

Gambar 12. Form Data Kriteria

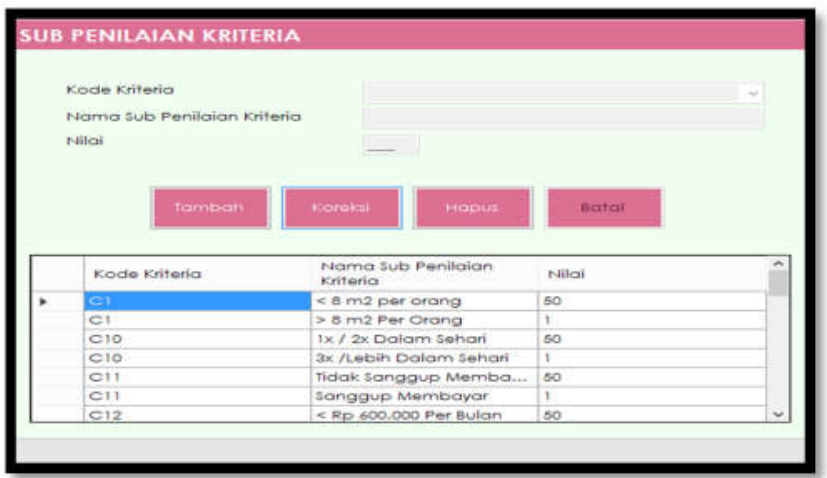

Gambar 13. Form Data Sub Penilaian Kriteria

\section{G. Laporan Hasil Penilaian Kelayakan KUBE}

Laporan hasil penilaian kelayakan KUBE merupakan hasil dari proses pengolahan data Penilaian Kelompok Usaha Bersama dengan menerapkan metode Weigthed Product pada Sistem Pendukung Keputusan, seperti terlihat pada Gambar 16. 
Jurnal Pseudocode, Volume VII Nomor 1, Februari 2020, ISSN 2355-5920, e-ISSN 2655-1845 www.ejournal.unib.ac.id/index.php/pseudocode

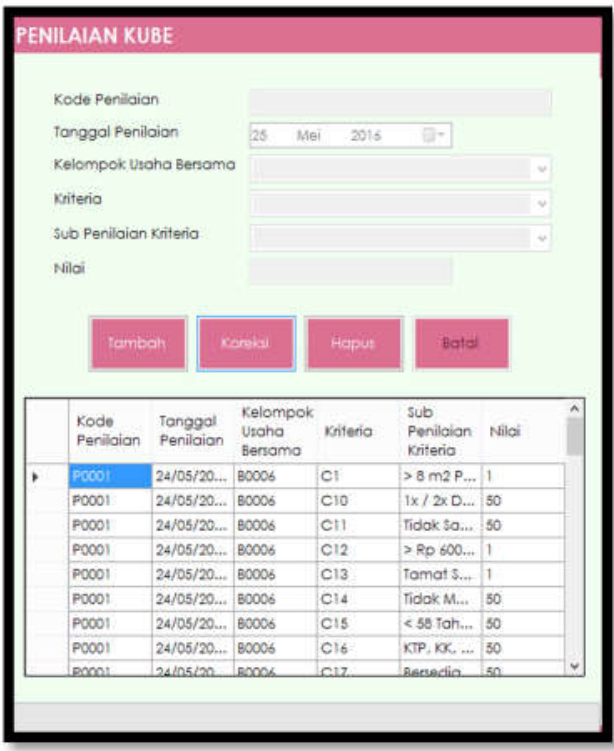

Gambar 14. Form Data Penilaian KUBE

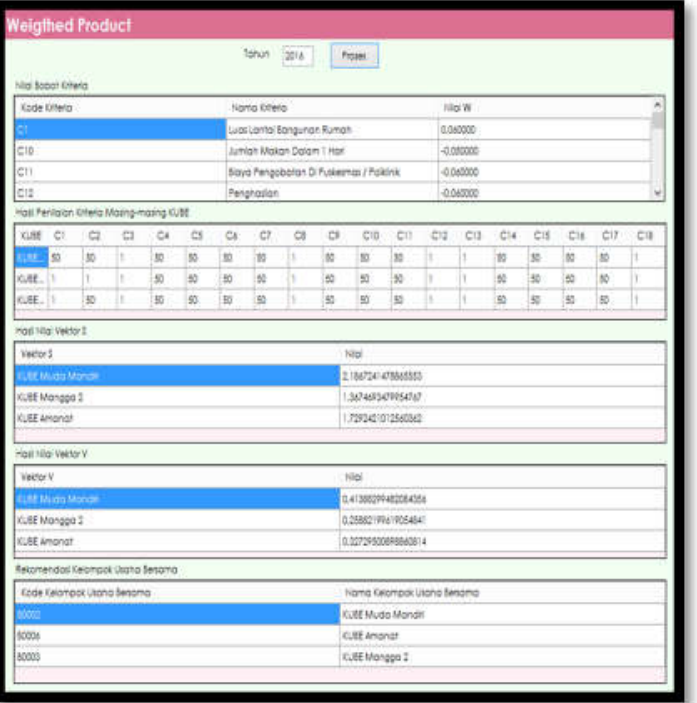

Gambar 15. Form Data Weighted Product

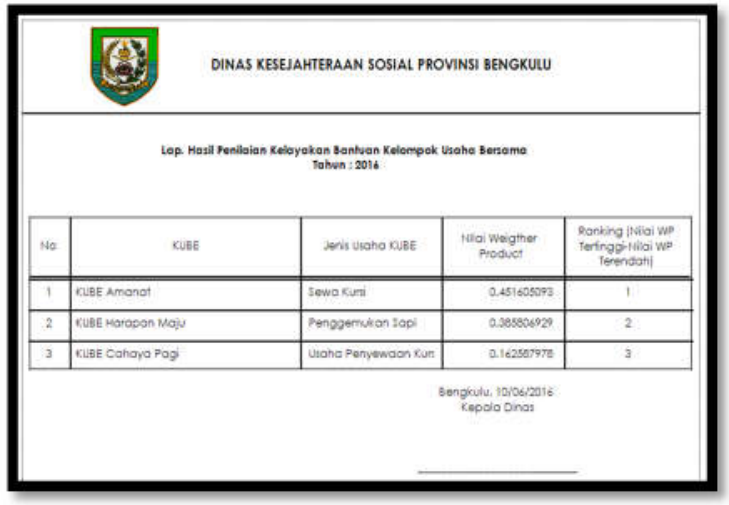

Gambar 16. Laporan Hasil Penilaian Kelayakan KUBE

\section{G. Hasil Pengujian}

Pengujian sistem dilakukan dengan menggunakan metode black box, yaitu dengan menguji form input data yang terdapat pada Aplikasi Pengadaan Barang ini. Pengujian dilakukan agar dapat diketahui kinerja dari aplikasi pengadaan barang. Adapun hasil pengujian dengan menggunakan metode black box yang penulis lakukan.

\section{KESIMPULAN}

Berdasarkan hasil dari pembahasan tersebut, maka dapat disimpulkan bahwa:

1. Sistem pendukung keputusan bantuan kelompok usaha bersama (KUBE) Pada Dinas Kesejahteraan Sosial Provinsi Bengkulu merupakan aplikasi yang dapat membantu dalam mengambil keputusan kelayakan pemberian bantuan kepada masing-masing Kelompok Usaha Bersama (KUBE).

2. Aplikasi ini telah menyediakan 18 (delapan belas) kriteria penilaian yang akan dinilai pada masing-masing KUBE. Hasil dari penilaian tersebut akan diproses menggunakan metode Weighted Product (WP), kemudian melakukan perankingan berdasarkan nilai WP yang paling tinggi.

3. Setelah melakukan pengujian sistem, maka didapati hasil aplikasi telah diberikan otentikasi sehingga pengguna yang tidak memiliki username dan password tidak dapat mengelola proses pengolahan data Sistem pendukung keputusan bantuan kelompok usaha bersama (KUBE). 
Jurnal Pseudocode, Volume VII Nomor 1, Februari 2020, ISSN 2355-5920, e-ISSN 2655-1845 www.ejournal.unib.ac.id/index.php/pseudocode

\section{REFERENSI}

[1] Adelia, dkk. 2011. Implementasi Customer Relationship Management (CRM) Pada Sistem Reservasi Hotel Berbasis Website dan Desktop. Jurnal Sistem Informasi Vol 6 No 2 September 2011:113-126. Fakultas Teknologi Informasi Universitas Kristen Maranatha.

[2] Alfita, Riza. 2012. Perancangan Sistem Pendukung Keputusan Penentuan Prioritas Produk Unggulan Daerah Menggunakan Metode Weighted Product (WP). Universitas Trunojoyo Madura. Journal.unipdu.ac.id.

[3] Buku Pedomanan Pelaksanaan Penanggulangan Kemiskinan Perkotaan Melalui Usaha Ekonomi Produktif Kelompok Usaha Bersama.
[4] Christian, V.M. Eduardo S. 2014. Sistem Pendukung Keputusan Kenaikan Jabatan Pada PT. Bank Central Asia Tbk (BCA) Menggunakan Metode Analityc Hierarchy Process. Universitas Dian Nuswantoro. Semarang. Eprints.dinus.ac.id.

[5] Aviluddin. 2009. Memahami Penggunaan Diagram Arus Data. Jurnal Informatika Mulawarman Vol.04 September 2009. Program Studi Ilmu Komputer, FMIPA Universitas Mulawarman.

[6] Hernita. 2010. Kupas Tuntas Database Server 2008. Penerbit Andi. Yogyakarta.

[7] Octafian, D. Tri. 2011. Desain Database Sistem Informasi Penjualan Barang (Studi Kasus : Minimarket Grace Palembang). Jurnal Teknologi dan Informatika (Teknomatika) Vol.1 No.2 Mei 2011. 